\title{
O CONCEITO DE SEGURANÇA NA PSICOLOGIA
}

\section{THE CONCEPT OF SECURITY IN PSYCHOLOGY}

\author{
Luís Antônio Monteiro Campos ${ }^{1}$, Felipe Xavier de Moraes²$^{2}$, Cláudio Manoel Luiz de Santana ${ }^{3}$
}

\author{
Submetido: 14/02/2021 \\ Aprovado: 08/03/2021
}

\begin{abstract}
RESUMO
Na busca pelo "conceito de segurança" em Psicologia, partiu-se da análise etimológica do termo, que, na consideração da tradição na qual foi gestado, sugeriu um sentido de crença. Investigou-se o processo de como um termo se transforma em conceito, também a definição de crença para a Ciência Psicológica, desvelando a área da Psicologia implicada no caso de uma abordagem genuinamente conceitual, neste caso, a Cognição Social, embora esta não privatizasse a temática. Gerou surpresa que o termo "segurança" tenha aparecido amiúde instrumentalizado; não conceituado. Tal foi a descoberta, entendida pelo fato da Psicologia trabalhar na ordem de um plano conceitual mínimo, dado seu objeto, a subjetividade, com suas múltiplas expressões, cuja dinamicidade dificulta a conceitualização.
\end{abstract}

PALAVRAS-CHAVE: Segurança. Conceito. Psicologia. Subjetividade. Instrumentalização.

\begin{abstract}
In the search for the concept of security in Psychology, we started from the etymological analysis of the term, which, in the consideration of the tradition in which it was born, suggested a sense of belief. The process of how a term becomes a concept and the definition of "belief" for Psychological Science were also investigated, uncovered by the area of Psychology involved in the case of a genuinely conceptual approach, in this case, social cognition, although it did not privatize the theme. We were surprised that the term "security" often appeared as an instrument - not a conception. That was the discovery, understood by the fact that Psychology works in the order of a minimal conceptual plan, given its object, subjectivity, with its multiple expressions, whose dynamism hinders conceptualization.
\end{abstract}

KEYWORDS: Security. Concept. Psychology. Subjectivity. Instrumentalization

\footnotetext{
1 campox1@gmail.com - Universidade Católica de Petrópolis e PUC-Rio

2 Cursa Mestrado em Psicologia na Universidade Católica de Petrópolis (UCP), tendo atuado na esfera de Gestão de Pessoas, Projetos Sociais e também no âmbito clínico. A dedicação à Clínica Psicológica se dá pelo atendimento em consultório particular, com abordagem orientada por formação em "Accelerated Experiential Dynamic Psychotherapy", oferecida pelo "Instituto AEDP-Brasil", em associação com "AEDP Institute of New York". Trata-se de abordagem fundada na esteira das Psicoterapias Integrativas, compartilhando pressupostos que vêm mantendo diálogo com os clínicos da Psicanálise, das Psicoterapias Breves, da Neurociência Afetiva,Teoria das Emoções, Experiências Somáticas, Teoria do Apego e Estudos do Desenvolvimento Infantil. https://orcid.org/0000-0002-2707-5593

${ }^{3}$ Mestrado em Psicologia pela Universidade Católica de Petrópolis(2020). É sacerdote (pároco) - Arquidiocese de São Sebastião do Rio de Janeiro. Tem experiência na área de Teologia e Psicologia, com ênfase em Clínica, Humanismo e Logoterapia. Temas: Autoconhecimento, Espiritualidade e Sentido de Vida.- https://orcid.org/0000$\underline{0001-7626-0878}$
} 


\section{RECIMA21 - REVISTA CIENTÍFICA MULTIDISCIPLINAR}

O CONCEITO DE SEGURANCA NA PSICOLOGIA

Luís Antônio Monteiro Campos, Felipe Xavier de Moraes, Cláudio Manoel Luiz de Santana

\section{INTRODUÇÃO}

Em busca da palavra "segurança" no Dicionário Etimológico Nova Fronteira da Língua Portuguesa, encontrar-se-á o remetimento - por Cunha - ao verbete "Seguro". Este é oriundo do termo latino "Securus", cuja significação designa o adjetivo do que é "livre de perigo, firme." 1 Já na acepção de Matos, no Dicionário de Filosofia Moral e Política, o significado trazido é o de "sem preocupações", etimologicamente sugerindo o sentido de "ocupar-se de si mesmo" "(se+cura)". ${ }^{2}$

Para a permanência na esteira da tradição latina na qual o termo "segurança" é gestado, tem-se no parecer de Matos que a designação mais comum dele é de "um mal a evitar" 3 , conforme a abordagem de Tomás de Aquino na Suma Teológica "(Aquino, século XIII, $1^{\text {a }}$ parte da $2^{\mathrm{a}}$ parte, questão 40, art. $8^{\circ}$ ). ${ }^{4}$ Daí se depreende a ideia de "segurança" na ordem da ausência de risco, do que é previsível, da certeza em relação ao futuro. O risco diz respeito ao que venha a diminuir a previsibilidade quanto ao que há de vir, enquanto a "segurança" suporá a crença em um futuro que repetirá o presente de acordo com a deliberação do referente, seja a pessoa ou grupo analisado. Isto quer dizer que se o presente deste estiver sendo um mal, a ele estará assegurado posteriormente um mal também, e nisto consistirá sua segurança. O pior, neste ensejo, não seria a reprodução do mal, mas sim se um bem despontasse neste horizonte, pois sua ocorrência consistiria no imprevisível, no qual se encontra a raiz de toda insegurança, segundo Matos. ${ }^{5}$

Matos observa o quanto tal concepção estaciona no plano da idealidade, dado o fato de ser inatingível a previsibilidade completa. Disso decorre uma compreensão da "segurança" como um daqueles patrimônios que o autor em questão denominará como sendo do tipo da "linha do horizonte", por ser tão inalcançável quanto. E nestes termos são dadas as condições para se trilhar um caminho que direcione para a área pela qual é do interesse aqui enveredar: a da Psicologia. Isto ficará evidente com o que se seguirá. ${ }^{6}$

Ocorre que a "segurança" enquanto ideal é passível de ser aplicada aos mais variados ramos da atividade humana. Matos apontará para a instrumentalização do referido conceito no

\footnotetext{
${ }^{1}$ CUNHA, Antônio Geraldo da. Dicionário Etimológico Nova Fronteira da Língua Portuguesa. 2 ed. Rio de Janeiro: Nova Fronteira, 1986, p. 711.

2 MATOS, L. S. de. "Segurança". Dicionário de Filosofia Moral e Política. 1. a série, coord. António Marques e Diogo Pires Aurélio. Lisboa: Instituto de Filosofia da Nova, 2012, p. 1. Disponível em: http://www.dicionariofmpifilnova.pt/. Acesso em: 18 out. 2020.

3 Ibidem apud AQUINO, S. T. de. Summa Theologica, in http://www.newadvent.org/summa/.

4 Ibidem, p. 1.

5 Cf. Ibidem.

${ }^{6}$ Cf. Ibidem.
} 


\section{RECIMA21 - REVISTA CIENTÍFICA MULTIDISCIPLINAR}

âmbito da técnica, da economia, da política, da esfera sentimental. ${ }^{7}$ Trata-se de um constructo amplo e com possibilidade de assumir uma multiplicidade de significados, porque se presentifica no "estar e sentir-se seguro perante ameaças ou perigos"8; isto para usar uma construção de Booth. Ameaças e perigos, como se sabe, são encontradas nas mais variadas frentes, o que abre inúmeras portas para se trabalhar o "conceito de segurança".

Há de convir que o tratamento do "conceito de segurança" no campo da crença, especialmente da crença em um ideal, conforme sugerido pela própria etimologia tanto quanto pela tradição na qual o termo foi engendrado, o da latinidade, permite à Psicologia apropriar-se deste objeto de estudo se valendo dele para fazer uma abordagem na esfera da Cognição Social. E a variável cognitiva evidenciada aqui é a da própria crença no ideal de segurança.

Acabará sendo inevitável à Ciência Psicológica o tratamento desta temática por este viés, sendo bem provável que se confirme o que por ora pode ser que não passe de uma presunção. Não obstante esta desconfiança, há fortes indícios de que se confirme esta hipótese. Por ela enveredará o presente trabalho, a fim de poder vislumbrar, mesmo que de forma parcial e limitada, como se mostra o "conceito de segurança" em Psicologia.

\section{SEDIMENTANDO AS BASES}

O pressuposto é de que o tratamento da temática requer fundamentações elementares. $\mathrm{O}$ "conceito de segurança" em Psicologia, nesta pesquisa trabalhado, passa pela definição até mesmo do que se entende por "conceito"; passa pela definição de "crença" para a Ciência Psicológica, ao se considerar a dimensão idealista que a própria noção de segurança consigo traz, requerendo um acreditar na permanência do presente no futuro, conforme visto anteriormente; supõe ainda uma observação quanto a qual área da Psicologia estaria sendo implicada quando de uma abordagem desta natureza.

\subsection{UMA DEFINIÇÃO DE CONCEITO}

O "conceito" é o que se expressa por uma linguagem simbólica da qual o conhecimento científico lança mão para poder ser comunicado, e carece do que se denomina "termo" como seu

\footnotetext{
7 Cf. Ibidem.

8 SANTOS, Álvaro Moreira dos. Segurança e Globalização: A Perspectiva dos Estudos Críticos de Segurança. Proelium $X \quad$ (10), p. 107-114, 2016. Disponível em: https://academiamilitar.pt/images/site images/Revista Proelium/07 Alvaro Santos.pdf. Acesso em: 19 out. 2020 apud BOOTH, Ken. Critical Security Studies and World Security. Boulder: Lynne Rienner Publishers, 2005, p. 13.
} 


\section{RECIMA21 - REVISTA CIENTÍFICA MULTIDISCIPLINAR}

veículo. ${ }^{9}$ Por "termo" entende-se "a unidade mínima da terminologia"10, sendo "um signo linguístico que difere da palavra, unidade da língua geral, por ser qualificado no interior de um discurso de especialidade"11. Para melhor compreensão, suponha-se que uma palavra pode assumir inúmeros significados, conforme se verifica em um dicionário na consideração do léxico da língua; um termo, por outro lado, manifesta-se como uma palavra também, é só que contextualizada no interior de um discurso, possuindo um referente de interpretação, um predicado vinculado. ${ }^{12}$ Depreende-se daqui que "o termo é uma designação que corresponde a um conceito em uma linguagem de especialidade."13

No estabelecimento da relação entre "termo" e "conceito" fica-se de imediato com o apontamento de Lara. Por ela assumido como "a palavra no discurso - o termo - associa-se a uma classe de objetos, às coisas do mundo real, tendo, dessa forma, uma extensão." ${ }^{14}$ É nesta acepção que palavras e expressões, isto é "os termos", fisicalizam conceitos, no dizer de Krüger, tornando-os passíveis de serem compreendidos e comunicados, tomados, por sua vez, enquanto entidades ideativas sem as quais seria impossível o desenvolvimento dos processos cognitivos, dados do ponto de vista simbólico, no que tange à pesquisa científica. ${ }^{15}$

No panorama desta pesquisa, a definição de "conceito" ora encontrada, pelo que se intui, se por um lado abre caminho para se trilhar uma base segura de um contexto específico, que é o da Psicologia, no qual o termo "segurança" vai ganhando corpo, conceitualizando-se e, enfim, tornandose cognoscível; por outro lado, propicia um choque de realidade, por deixar claro que o mesmo chão que fornece o amparo de que se precisa para a cognoscibilidade, vir a ser exatamente aquele que impõe os limites à pretensão de conceituar universalmente, demonstrando a parcialidade da tarefa a que se propõe tal ensaio. Neste ensejo, parte-se do pressuposto de que o território dado será o mesmo que imporá as fronteiras, ficando evidente quão dialética será a tarefa de conceituar "segurança" na frente em que este trabalho labuta.

\subsection{UMA DEFINIÇÃO DE CRENÇA PARA A CIÊNCIA PSICOLÓGICA}

\footnotetext{
9 Cf. KRÜGER, Helmuth Ricardo. Fundamentos da Psicologia Social. Tese (Doutorado em Psicologia) Fundação Getúlio Vargas (Instituto Superior de Estudos e Pesquisas Psicossociais - Centro de Pós-graduação em Psicologia). Rio de Janeiro, 1984, p. 121.

10 LARA, Marilda Lopez Ginez de. Diferenças conceituais sobre termos e definições e implicações na organização da linguagem documentária. Ci. Inf., Brasília , v. 33, n. 2, p. 92, ago. 2004. Disponível em <http://www.scielo.br/scielo.php?script=sci_arttext\&pid=S0100-19652004000200009\&lng=pt\&nrm=iso>. http://dx.doi.org/10.1590/S0100-19652004000200009. Acesso em 23 de out. 2020.

11 Ibidem, p.92.

12 Cf. Ibidem, p. 92.

13 Ibidem, p.92.

14 Ibidem, p.92.

${ }^{15}$ Cf. KRÜGER, Helmuth Ricardo, op. Cit., p. 126.
} 


\section{RECIMA21 - REVISTA CIENTÍFICA MULTIDISCIPLINAR}

Uma definição mais geral do termo "crença" trazida pelo Dicionário de Psicologia da APA (American Psychological Association) faz menção à "aceitação da verdade, realidade ou validade de algo."16 Diniz vai afirmar que diz respeito ao ato de acreditar, assim como no seu efeito, considerando-se o "acreditar" aqui na significação de tomar por verdade. ${ }^{17}$ As crenças estariam na ordem de um conteúdo mental simbólico manifestado ao modo de afirmativas através das quais emergem as presunções, aquilo no que se acredita, o que se julga ser melhor ou pior, o que se supõe ser necessário, delineando, justificando interpretativamente o que de forma pessoal foi sendo experienciado. $^{18}$

$\mathrm{Na}$ dependência da dimensão experiencial, as crenças parecem se evidenciar, na concepção de Rokeach, de alguma forma psicológica, sem obedecer estritamente a uma organização lógica, porque emergem, amiúde, segundo ele, de razões que de maneira consciente ou inconsciente, seja no nível pessoal ou social o sujeito se constrangeria em admitir; o que justifica o caso de alguém dizer acreditar em algo quando, nem sempre, aquilo corresponde de verdade ao que acredita. ${ }^{19}$ Krüger entenderá esta dinâmica à luz da função que as crenças assumem:

Em cognições sociais são as crenças que nos orientam na busca da oportunidade para a interação social desejada, do objetivo a ser alcançado, na escolha do local, da estrutura e do conteúdo informativo a ser possivelmente tratado, na pretendida interação social. Após o estabelecimento do contato, outras crenças vão sendo continuamente obtidas, reformuladas e outras abandonadas pelas pessoas em interação. ${ }^{20}$

Krüger dá indícios das crenças terem importante função dentro do processo de interação social. Embora na abordagem cognitivista sejam oriundas da consciência, presentificando-se nas mais variadas experiências que o sujeito reúne cognitivamente, emocionalmente e comportamentalmente, ainda assim não se resumem a se constituírem nesta frente; também eclodem, transformam-se e são deixadas de lado a partir do contato, das relações entre os indivíduos, com tendência a se organizarem em sistemas de crenças. ${ }^{21}$

No intuito de favorecer a compreensão do modus operandi deste tipo de sistema, Krüger cita os papéis sociais enquanto sistemas de crenças. Tais papéis são de grande importância na esfera do comportamento dos sujeitos em interação, e isto se deve ao caráter normatizador que surge na crença do indivíduo no tocante ao modo de proceder relativo ao papel exercido: visando melhor

16 VANDENBOS, Gary R (Org.). Dicionário de Psicologia da APA. Trad. Daniel Bueno, Maria Adriana Veríssimo Veronese, Maria Cristina Monteiro. Porto Alegre: Artmed, 2010, p. 239.

17 DINIZ, António M. Sobre essas coisas a que chamamos crenças: para uma propedêutica da psicologia da crença. Forte da Casa: Climepsi Editores, $2004 . \quad$ Disponível em:https://www.researchgate.net/profile/Antonio_Diniz/publication/308048922_Sobre_essas_coisas_a_que_cha mamos_crencas_para_uma_propedeutica_da_psicologia_da_crenca/links/57d̄81933008ae5f03b4984882/Sobreessas-coisas-a-que-chamamos-crencas-para-uma-propedeutica-da-psicologia-da-crenca.pdf. Acesso em 24 de out. de 2020, p. 8

18 Cf. KRÜGER, Helmuth (Org.). Cognição Social: teoria, pesquisa e aplicações. Curitiba: CRV, 2018, p. 21.

19 Cf. ROKEACH, Milton. Crenças, atitudes e valores. Trad. de Angela Maria Magnan Barbosa; revisão técnica de Helmut Ricardo Kruger. Rio de Janeiro: Editora Interciência, 1981, pp. 1-2.

20 KRÜGER, Helmuth (Org.), op. Cit., p. 22.

21 Cf. Ibidem, pp. 21-22. 
Luís Antônio Monteiro Campos, Felipe Xavier de Moraes, Cláudio Manoel Luiz de Santana

interação, espera-se que certo sujeito aja de determinada maneira considerando a sua posição social, sua profissão ou religião, por exemplo. Isto posto, vale que se remeta ao surgimento de expectativas comportamentais dentro deste contexto. ${ }^{22}$ As crenças daqui decorrentes, para usar uma terminologia de Barcelos, seriam indicadoras de comportamentos futuros. ${ }^{23}$

Não é intuito agora tratar do tema das crenças aprofundando mais do que até o presente momento foi necessário, haja vista o enveredamento pela trilha proposta obedecer ao objetivo desta pesquisa. Viu-se que existe uma crença inerente ao "conceito de segurança": a de se supor a permanência do presente no futuro. Isso relaciona ambos os conceitos: segurança e crença. $O$ que há em comum entre os dois, e que saltou aos olhos, foi a projeção para o futuro, um certo idealismo, que no caso do primeiro (do conceito de segurança) presume que o que há de vir será como o que está sendo, tomando-se por ideal que isto fique exatamente assim, extirpando-se neste ensejo o risco. No caso do segundo (do conceito de crença), ao referir ao sistema de crenças, precisamente a um destes, os papéis sociais, há um ideal de comportamento esperado para o exercício de cada papel e, portanto, uma expectativa para a realidade póstuma.

\subsection{QUANTO À ÁREA DA PSICOLOGIA QUE ESTÁ SENDO IMPLICADA}

No âmbito da Ciência Psicológica existe um campo de estudo denominado Cognição Social, decorrente do estabelecimento de relações entre a Psicologia Cognitiva e a Psicologia Social. ${ }^{24}$ Trata-se de uma abordagem cujo intuito é favorecer a compreensão e explicação acerca da maneira como os sujeitos se percebem a si próprios e aos demais, e sobre como tais percepções vêm a criar condições a certa visada sobre o comportamento social que propicie mais facilmente explicá-lo, fazer previsões a seu respeito e orientá-lo. Esta é a ótica de Garrido, Azevedo e Palma, que apontaram para mais uma especificidade deste tipo de leitura, quanto ao modo dos fenômenos sociais serem abordados: "através das investigações das estruturas e processos cognitivos pelos quais operam." 25 Por aí se encaminha o estudo haurido da busca dos fundamentos cognitivos dos fenômenos sociais, pautado pela integração do que a Psicologia Cognitiva tematiza em termos teóricos e metodológicos, tais como percepção, memória e pensamento, articulando isso com as discussões existentes no âmbito da Psicologia Social. ${ }^{26}$

\footnotetext{
22 Cf. Ibidem, p. 22.

23 Cf. BARCELOS, Ana Maria Ferreira. Metodologia de pesquisa das crenças sobre aprendizagem de línguas: estado da arte. Rev. bras. linguist. apl., Belo Horizonte , v. 1, n. 1, p. 71-92, 2001. Disponível em <http://www.scielo.br/scielo.php?script=sci_arttext\&pid=S198463982001000100005\&lng=en\&nrm=iso $>$.https://do i.org/10.1590/S1984-63982001000100005. Acesso em 25 de out. de 2020, p. 76.

${ }^{24}$ Cf. DORSCH, Friedrich; HÄCKER, Hartmut; STAPF, Kurt-Hermann. Redação de Horst Ries. Trad. de Emmanuel Carneiro Leão e equipe. 4. ed. Petrópolis: Vozes, 2009, p. 153.

25 GARRIDO, Margarida Vaz; AZEVEDO, Catarina; PALMA, Tomás. Cognição social: Fundamentos, formulações actuais e perspectivas futuras. Psicologia, Lisboa , v. 25, n. 1, p. 113-157, jun. 2011. Disponível em <http://www.scielo.mec.pt/scielo.php?script=sci_arttext\&pid=S0874$20492011000100006 \&$ Ing=pt\&nrm=iso >. Acesso em 27 de out. de 2020, p. 116.

26 Cf. Ibidem, p. 116.
} 


\section{RECIMA21 - REVISTA CIENTÍFICA MULTIDISCIPLINAR}

A produção do conhecimento social se funda, neste contexto, em estruturas cognitivas em que se processa a informação sob a égide das teorias, diferentemente de uma abordagem com a orientação de encaminhar suas análises tomando os dados como parâmetros. ${ }^{27} \mathrm{~A}$ tomada da interação entre os sujeitos e destes com o ambiente em vista das trocas aí estabelecidas, na ótica da Cognição Social, é algo muito favorável para a compreensão desta dinâmica, uma vez que nas relações se dão a obtenção e o processamento de informações por meio das quais os juízos emergirão, donde se dá a influência - de sobremaneira - quanto às tomadas de decisões, e, neste caso, por um processo cognitivo. ${ }^{28}$

O ser humano é influenciado por processos cognitivos considerados basilares para a leitura da realidade social na qual está imerso, que podem induzir a equívocos em certas situações, caso esteja impelido por um olhar que venha a distorcer as imagens dos entes à volta, quando atravessado por formas de pensar dadas aos esquemas mentais pré-estabelecidos, à heurística (que revela o quanto o homem é um avaro cognitivo, pela frequência com que pega atalhos para mais rapidamente tirar conclusões acerca da realidade social), quando também se deixa levar pelo automatismo (comportamentos inconscientemente reproduzidos). ${ }^{29}$ É mister, na temática agora abordada, trilhar este caminho, porque a pesquisa sobre o conceito de segurança mostrou haver uma relação intrínseca, na tradição latina em que o termo foi engendrado, entre o referido conceito e a ideia de crença: a segurança se funda na crença de que o futuro repetirá o presente. As crenças, por sua vez, estão na contextura de um pressuposto que é objeto de estudo da Cognição Social, neste caso o que se denomina "esquema", esquema esse que Krüger definirá como sistema de crenças. ${ }^{30}$

Chegado a este ponto, poder-se-ia perguntar: Por que especificar a área da Psicologia implicada na análise do conceito de segurança, quando o tema da "segurança" propriamente já aparece na Psicologia Organizacional, do Trânsito (nestas duas frentes, mais voltado para a Segurança Psicológica), na Psicologia Humanista de Maslow (em sua teoria hierárquica das necessidades), na Teoria do Apego de John Bowlby? Por conta, claro, de se querer encaminhar esta empreitada para a tarefa de conceituar o termo em questão, tentando averiguar que campo da Ciência Psicológica mais favoreceria neste sentido, sobretudo porque, quando se cogitou pesquisar sobre este assunto, a princípio aparentemente fácil, surgiu uma dificuldade com a qual não se estava contando, a de não se ter encontrado - pelo menos na busca aqui realizada - a referida definição conceitual em Psicologia, em razão do "conceito de segurança" aparecer de modo geral

27 Cf. CABECINHAS, Rosa. Representações sociais, relações intergrupais e cognição social. Paidéia (Ribeirão Preto), Ribeirão Preto , v. 14, n. 28, p. 125-137, Aug. 2004 . Available from <http://www.scielo.br/scielo.php?script=sci_arttext\&pid=S0103-863X2004000200003\&lng=en\&nrm=iso>. https://doi.org/10.1590/S0103-863X2004000200003. Acesso em 27 de out. de 2020, p. 131.

28 Cf. RODRIGUES, Aroldo; ASSMAR, Eveline Maria Leal; JABLONSKI, Bernardo. Psicologia Social. 32. ed. Petrópolis: Vozes, 2015, p. 76.

${ }^{29}$ Cf. Ibidem, pp. 76-77.

30 Cf. KRÜGER, Helmuth (Org.), op. cit., p. 21. 


\section{RECIMA21 - REVISTA CIENTÍFICA MULTIDISCIPLINAR}

instrumentalizado. Parece até que este trabalho, sem querer ser tão pretencioso, vai na direção de certo pioneirismo quanto a isso.

A análise conceitual, em estrito senso, compreenderá necessariamente a contextualização de um termo; no caso aqui: "segurança". Partiu-se de sua raiz etimológica, passando pela evolução dos significados da palavra, até se chegar ao campo específico no qual seria vislumbrado: aqui o da Psicologia. Por estes vieses, o etimológico e o da tradição latina a que remonta o termo "segurança", apareceu uma relação intrínseca entre segurança e crença, que na conceituação a que se predispõe o campo da Psicologia, leva ao estabelecimento de uma conexão com a área da Ciência Psicológica imediatamente implicada: a da Cognição Social. Ela, por sua vez, tem as crenças como um dos objetos dos quais foi se apropriando em suas análises. Com isso não se tem a pretensão de afirmar que, em Psicologia, o "conceito de segurança" seja uma propriedade privada da Cognição Social, até porque pode ser tratado por qualquer outra área desta ciência, conforme foi visto. Mas a menos que não se queira fazer uma abordagem genuinamente conceitual, prescindiria-se com tranquilidade da implicação ora apontada; trabalhando conceitualmente, por outro lado, seria honesto ao menos margear a ideia de que no "conceito de segurança" há uma variável cognitiva (crenças) implicada com a esfera da Cognição Social.

\section{A PSICOLOGIA E O CONCEITO DE SEGURANÇA}

Retome-se resumidamente a colocação de Lara, complementada por Krüger, quanto ao processo de construção do conceito. Um termo (unidade mínima da terminologia), que pode ser uma palavra também (sendo a palavra a unidade da língua geral), vem a se transformar em conceito quando contextualizado no interior de um discurso de especialidade. Existe o elemento contextual e o da especificidade discursiva na qual o termo opera para poder se apresentar conceitualmente, ${ }^{31}$ sendo este modus operandi a condição sine qua non para a cognoscibilidade desta entidade ideativa, que é o conceito, porque fisicalizado pelos remetimentos do termo nas ligações por ele estabelecidas com as coisas do mundo real. ${ }^{32}$

A razão por que se introduziu a terceira seção deste artigo com um resumo do processo de construção do conceito, ao ser relacionada, neste tópico, a Psicologia e o "conceito de segurança", deveu-se à necessidade de se fazer o seguinte esclarecimento: se a proposta é de tratar a questão aos moldes conceituais, no presente caso a "segurança", há de se delimitar dentro de que esfera este termo haverá de ser tratado, até porque só será possível transformar um termo em conceito no

31 Cf. LARA, Marilda Lopez Ginez de. Diferenças conceituais sobre termos e definições e implicações na organização da linguagem documentária. Ci. Inf., Brasília , v. 33, n. 2, p. 92, ago. 2004. Disponível em <http://www.scielo.br/scielo.php?script=sci_arttext\&pid=S0100-19652004000200009\&lng=pt\&nrm=iso>. http://dx.doi.org/10.1590/S0100-19652004000200009. Acesso em 23 de out. 2020, p. 92.

32 Cf. KRÜGER, Helmuth Ricardo. Fundamentos da Psicologia Social. Tese (Doutorado em Psicologia) Fundação Getúlio Vargas (Instituto Superior de Estudos e Pesquisas Psicossociais - Centro de Pós-graduação em Psicologia). Rio de Janeiro, 1984, p. 126. 


\section{RECIMA21 - REVISTA CIENTÍFICA MULTIDISCIPLINAR}

interior de determinado contexto, que aqui será o da Psicologia, que decifrará o código contido no simbolismo inerente à conceitualidade através de um aparato discursivo específico. Explicitar que contexto é esse, o da Ciência Psicológica, e que aparato discursivo the é peculiar, enquanto instrumental para discorrer sobre o termo "segurança", termo com todos os seus remetimentos a situações do mundo real no processo que o transformará em conceito, será fundamental a partir daqui, sem esquecer que o chão dado para se caminhar seguramente por esta vereda é o mesmo que imporá os limites, evidenciando de antemão a limitação desta empreitada.

\subsection{QUE CONTEXTO É ESSE, O DA CIÊNCIA PSICOLÓGICA?}

Bock, Furtado e Teixeira dirão ser um contexto marcado pela presença de diferentes escolas psicológicas, cujo trabalho produz um conhecimento caracterizado pela fragmentação. Isto se explica pela maneira como a própria Psicologia será entendida enquanto ciência. Em sentido lato: "Objeto específico, linguagem rigorosa, métodos e técnicas específicas, processo cumulativo do conhecimento e objetividade fazem da ciência uma forma de conhecimento." ${ }^{33}$ Tudo isso parece não ocorrer com a Psicologia, tanto quanto com a Antropologia, a Economia, a Sociologia e com todas as Ciências Humanas. ${ }^{34}$

$\mathrm{Na}$ consideração das mais variadas correntes psicológicas, notar-se-á umas se afirmarem integradas ao campo das Ciências do Comportamento, enquanto outras estarão mais vinculadas às Ciências Sociais ou da Saúde. No entanto, Bock, Furtado e Teixeira partirão do pressuposto de que, de acordo com a proposta por eles apresentada, a Psicologia estaria melhor compreendida se situada no quadro das denominadas Ciências Humanas, aproximada da História, da Antropologia, da Economia etc. ${ }^{35}$

Nas ciências ditas humanas, cada uma delas enfoca uma parte específica de seu objeto, que é o próprio homem: sujeito e concomitantemente objeto de estudo. Na ciência, em sentido lato, não há o risco de o cientista vir a se confundir com o fenômeno por ele estudado, o que nas Ciências Humanas acontece, fazendo com que o pesquisador venha a contaminar a sua pesquisa, considerando ir para ela com certa concepção de ser humano. Havendo uma multiplicidade de concepções quanto a isso, haverá uma diversidade de seres humanos a ser concebida e, por conseguinte, diversos objetos a serem estudados. E a Psicologia, atravessada por tais meandros, ao se debruçar sobre os fenômenos psicológicos, estará em uma situação na qual estes não poderão ser analisados univocamente. ${ }^{36}$ Destarte: "não podem ser submetidos aos mesmos padrões de descrição, medida, controle e interpretação." ${ }^{37}$ Segue-se, então, a inferência de Japiassu:

\footnotetext{
${ }^{33}$ BOCK, Ana; FURTADO, Odair; TEIXEIRA, Maria. Psicologias. 14. ed. São Paulo: Saraiva,2008, p. 21.

${ }^{34}$ Cf. Ibidem.

35 Cf. Ibidem, p. 24.

36 Cf. Ibidem, p. 22.

37 Ibidem, p. 22.
} 


\title{
RECIMA21 - REVISTA CIENTÍFICA MULTIDISCIPLINAR
}

O CONCEITO DE SEGURANÇA NA PSICOLOGIA

Luís Antônio Monteiro Campos, Felipe Xavier de Moraes, Cláudio Manoel Luiz de Santana

"Consequentemente, e por sólidas razões, não somente históricas mas doutrinárias, torna-se impossível à Psicologia assegurar-se uma unidade metodológica. (...)"38. No mais: "Por isso, talvez fosse preferivel falarmos, ao invés de "Psicologia", em "Ciências Psicológicas" ${ }^{39}$

O exposto acima insinua a razão pela qual a Psicologia se desdobra em inúmeras tendências ou escolas, não obstante algum sentido de unidade precisar ocorrer e algum objeto de estudo mais específico a se definir, até pela necessidade do conhecimento daqui desdobrado se configurar enquanto ciência, haja vista o conhecimento científico - para que assim o seja - requerer algo específico a ser estudado. O ser humano, claro, com todas as suas expressões, será a matéria prima de onde partirão as análises em Psicologia, que se predisporá a se debruçar sobre os mais variados objetos, como o comportamento humano, o inconsciente, a consciência, a personalidade, entre outros. Tudo isso que pode estar sintetizado no que parecerá ser o objeto central da Ciência Psicológica: a subjetividade. ${ }^{40}$

A Psicologia - enquanto ciência -, desejosa em colaborar para a compreensão da totalidade da vida humana, entraria com o estudo da subjetividade:

\begin{abstract}
A subjetividade é a síntese singular e individual que cada um de nós vai constituindo conforme vamos nos desenvolvendo e vivenciando as experiências da vida social e cultural; é uma síntese que de um lado nos identifica, por ser única; e de outro lado nos iguala, na medida em que os elementos que a constituem são experienciados no campo comum da objetividade social. Essa síntese - a subjetividade - é o mundo de ideias, significados e emoções construído internamente pelo sujeito a partir de suas relações sociais, de suas vivências e de sua constituição biológica; é, também, fonte de suas manifestações afetivas e comportamentais. ${ }^{41}$
\end{abstract}

Em Psicologia, a tomada da subjetividade como síntese dos objetos todos de estudo realmente traz o traço de unidade que se fazia necessário para que se pudesse referir a uma denominada Ciência Psicológica. Todavia, a abordagem do respectivo objeto sintetizador não deixaria de diferir de acordo com a concepção de ser humano trazida por cada escola psicológica em particular, ao se avaliar a maneira como foi dado historicamente o desenvolvimento da Psicologia. As mais variadas vertentes aqui se fariam portadoras de um conhecimento fragmentário, no entanto parte integrante de um todo que é o ser humano: sua subjetividade com as suas mais variadas manifestações. ${ }^{42}$

Tal encaminhamento foi feito, precisa-se lembrar, na tentativa de situar o contexto em que 0 termo "segurança" se transformaria em conceito, já que para tal o meio é mister importante e condição sine qua non para a conceitualização. Inicialmente, a partir da análise etimológica da palavra e da descoberta da tradição em que foi gestada, ao envolver um sentido de crença, intuiu-se a relação imediata com o campo da Cognição Social, entendendo que este não a privatizaria, até porque o conceito apareceu instrumentalizado em inúmeras abordagens psicológicas. Em uma

\footnotetext{
${ }^{38}$ Ibidem, p. 30 apud Japiassu, Hilton. A Psicologia dos Psicólogos. 2. ed. Rio de Janeiro: Imago, 1983.

39 Ibidem, p. 30 apud Ibidem.

40 Cf. Ibidem, p. 22.

41 Ibidem, pp. 22-23

42 Cf. Ibidem, p. 24.
} 


\section{RECIMA21 - REVISTA CIENTÍFICA MULTIDISCIPLINAR}

ciência tão fragmentada como a Psicologia, conforme atestou-se, não surpreende que seja assim, e que seja assim também que se conceitue, de forma muito parcial mesmo, de modo a justificar o porquê do "conceito de segurança" tender a aparecer instrumentalizadamente.

Ocorre que nenhuma conceitualização em Psicologia será tão geral a ponto de valer para o seu universo como um todo, e nem sequer para uma abordagem como um todo, precisando ocorrer de acordo com a necessidade de instrumentalização. Ademais, para uma ciência que tem a subjetividade como síntese dos objetos todos de estudo, assim como das mais variadas expressões do ser humano, não poderia ser diferente, como não poderia ser diferente a definição de "segurança" pelo "Dicionário de Psicologia APA", colocada na ordem da sensação, particularmente sensação de proteção, confiança e libertação da apreensão, que vem a desenvolver a "Força de Ego". ${ }^{43} \mathrm{Nada}$ mais subjetivo que a sensação, e se o "conceito de segurança" vem a ser definido desta maneira, decorre do contexto em que ele o é, marcadamente de subjetivação.

\subsection{QUE APARATO DISCURSIVO É ESSE, O DA CIÊNCIA PSICOLÓGICA?}

A concepção de Guirado parece ajudar a formular uma resposta para esta pergunta, e que vem ao encontro do que se construiu nesta pesquisa até o momento, seja na forma como a Psicologia se mostra em seu contexto, seja na maneira como ela conceitua. O âmbito da Ciência Psicológica, conforme foi visto, é caracterizado pela tendência à subjetivação, e o citado autor compreende a Psicologia, na sua Análise Constitucional do Discurso, do ponto de vista de uma Analítica da Subjetividade, na aproximação que faz com a Psicanálise de Freud, com a Sociologia de Guilhon Albuquerque, com a Linguística Pragmática da Análise do Discurso de Dominique Maingueneau e com as reflexões de Michel Foucault. ${ }^{44}$

Da Psicanálise vem a voz que é dada a subjetividade, e que emerge da clínica, território por excelência das práticas psicológicas e psicanalíticas; da dita Sociologia, o que se desenvolve são exercícios ou relações socialmente estabelecidas que se repetem e são legitimadas pelos atores que reconhecem ou não, no plano das representações, o que vem deste universo de subjetivação; da Análise do Discurso, o senso de comunidade discursiva aparece preconizando a linguagem como discurso, quer dizer, dependente do contexto em que é produzida para ser compreendida; das reflexões de Michel Foucault, o discurso assimilado como ato, elemento circulante, sendo aquilo pelo que se luta nas relações de poder, ele aparece assumindo o papel de instrumento de construção de saberes, verdades e subjetividades. ${ }^{45}$

${ }^{43}$ Cf. VANDENBOS, Gary R (Org.), op. cit., p. 829.

44 Cf. GUIRADO, Marlene. Clínica e transferência na sombra do discurso: uma analítica da subjetividade. Psicol. USP, São Paulo, v. 26, n. 1, pág. 108-117, abril de 2015. Disponível em $<$ http://www.scielo.br/scielo.php?script=sci_arttext\&pid=S0103-65642015000100108\&lng=en\&nrm=iso >. acesso em 07 de novembro de 2020. https://doi.org/10.1590/0103-656420140022. Acesso em 07 de nov. de 2020, p. 108.

${ }^{45}$ Cf. Ibidem, pp. 108-109. 


\section{RECIMA21 - REVISTA CIENTÍFICA MULTIDISCIPLINAR}

No prisma desta Análise Institucional do Discurso, evidencia-se um método ou uma estratégia de pensamento acolhida pela região fronteiriça dos saberes por Guirado delineados, cuja operação se dá através de um campo conceitual mínimo, do que decorre a identificação da Psicologia como "instituição do conhecimento e da prática profissional"46. Trata-se de uma ciência embasada no agir dos atores implicados no cenário ora referido, independentemente de onde se dê, com procedimentos sustentados em conhecimentos por estes mesmos atores legitimados, por meio do que fica definido um plano de ação e o reconhecimento de um objeto como próprios. ${ }^{47}$

A descoberta neste instante realizada, na busca pelo "conceito de segurança" na Psicologia, permitiu o contato com a máquina conceituadora desta ciência, que como em qualquer outra ciência fica na dependência do contexto e do aparato discursivo nos quais se desenvolve. O contexto, conforme visto, explicita-se na tessitura do processo de subjetivação, ao se considerar como síntese dos objetos todos da Psicologia: a subjetividade. O aparato discursivo, estruturador do sistema contextual, desdobrado a partir do lugar de onde emerge a linguagem subjetivizadora, ou seja, a clínica, pela validação das produções simbólicas entre os atores envolvidos neste processo, que traz o senso de comunidade discursiva, e, por sua vez, empodera tais membros dotando-lhes de autoridade em seus consensos, traz certas peculiaridades, sobre as quais o presente trabalho brevemente se debruça desejoso de chegar a um objetivo primeiro, que é averiguar a maneira como o "conceito de segurança" se mostra na Psicologia. Por outro lado, há a impressão de que o descoberto irá mais na direção de como qualquer outro conceito pode vir a aparecer nesta ciência, o que não traz frustração, porque a natureza da pesquisa - em algumas situações - tem a ver com o deparar-se com o inesperado mesmo de quando em vez, podendo ser este o caso.

A Psicologia, em Guirado, atua no chão marcado por um plano conceitual mínimo, que se dá por conta da maneira como tal ciência é feita: enquanto instituição do conhecimento e da prática profissional, definindo um plano de ação e um objeto como próprios, conforme já foi visto. Fica explícito o porquê de tanta dificuldade em empreender aquilo que esta pesquisa se predispôs a fazer, que foi buscar o "conceito de segurança" na Psicologia, sendo que a impressão dada no momento é a de que, excetuando os conceitos clássicos, sejam eles os da Psicanálise e de alguns campos da Psicologia mais consolidados, se for pensar em id, ego e superego, transferência e contratransferência, relação terapêutica, entre outros; fora estes, quaisquer outros conceitos seriam de grande dificuldade igualmente para serem pesquisados. Ademais, não pode-se perder de vista 0 fato do plano conceitual na Ciência Psicológica ser mínimo mesmo, e assim o é porque constrói seu conhecimento a partir da ação em uma prática profissional, definindo neste ensejo a síntese de seus objetos todos como sendo, em última instância, a subjetividade nas suas múltiplas expressões, o que revela a dinamicidade deste mesmo objeto, que por um lado justifica que o "conceito de segurança" apareça instrumentalizado (porque gerido na prática profissional) e, por outro, porque pode aparecer

\footnotetext{
46 Ibidem, p. 108.

47 Cf. Ibidem, p. 108.
} 


\section{RECIMA21 - REVISTA CIENTÍFICA MULTIDISCIPLINAR}

abordado nos mais variados campos da Psicologia, haja vista ser dinâmico o objeto próprio desta ciência, vindo a dinamizar tudo mais inerente a ele.

\section{CONCLUSÃO}

Partiu-se para a presente pesquisa com a falsa impressão de que seria tarefa fácil trazer à tona o "conceito de segurança" na Psicologia. Por parecer um tanto quanto óbvia a importância da questão, subestimou-se o despontar de qualquer grande dificuldade. Contudo, à medida que se empreendeu a busca de material, tinha-se a impressão do afastamento cada vez maior da elementariedade desta tarefa. A propósito, a pretensão era de fazer algo elementar realmente: era só definir um conceito.

Definição conceitual de segurança, houve demasiada dificuldade em sua busca. Tinha-se, amiúde, a questão sendo tematizada instrumentalizadamente. Era preciso algum ponto de partida, daí a iniciativa de começar pela análise etimológica do termo, com remetimento, em seguida, ao movimento de transformação do termo em conceito. Como na tradição em que a palavra "segurança" foi gestada havia alguma relação com certo idealismo ou crença, foi averiguado o que seria "crença" para a Ciência Psicológica, subsequentemente inferindo a área da Psicologia diretamente implicada no caso de uma análise genuinamente conceitual, embora não faltasse clareza acerca da impossibilidade de aprisionamento do assunto no interior deste campo, entendido ser o da Cognição Social. Feito o percurso até este ponto, despontou-se a presunção de pioneirismo, a cogitação de dar uma significativa contribuição à ciência aqui praticada, no tratamento de um tema aparentemente simples, mas com sinais de que poucos haviam se atentado de tomá-lo da maneira como, inclusive, este trabalho teve a pretensão de tomar. Não muito, e logo declinou tal ambição. Ocorre que a conceituação está na dependência da inserção de um termo no interior de um dado contexto, sob o influxo de específico aparato discursivo. Contextualmente, a Psicologia se coloca em posição de tomar a subjetividade como síntese de seus objetos todos de estudo, com fortes tendências à subjetivação, e se a definição do objeto Ihe garante a unidade enquanto saber científico, a tendência subjetivizadora explica sua divisão interna em várias correntes ou abordagens, pelas quais o termo "segurança" vai se deslocando e assumindo dinamicamente, de forma instrumentalizada, as mais variadas acepções. Descobriu-se ser por conta da Ciência Psicológica ser feita no âmago de uma prática profissional, cujo discurso assumido como ato estabelece característico conhecimento que opera dentro de um campo conceitual mínimo, que a situação seja essa.

Evidencia-se, então, que o "conceito de segurança", assim como qualquer outro conceito que não os mínimos historicamente necessários para o plano de uma ciência que tem sua gênese na práxis, muita dificuldade teria de enquadramento conceitual. Além do mais, conceituar, definir, não deixa de ser uma maneira de aprisionar; no caso da Psicologia, o inaprisionável, seja o que sintetiza seus objetos todos (a subjetividade), seja tudo mais que a expressa, como por exemplo as 


\section{RECIMA21 - REVISTA CIENTÍFICA MULTIDISCIPLINAR}

sensações, na esteira das quais, inclusive, a "segurança" é colocada e, consequentemente, dinamizada pelo vislumbre subjetivizador da Ciência Psicológica, o que a faz realmente se mostrar com vistas à instrumentalização.

\section{REFERÊNCIAS}

Barcelos AMF. Metodologia de pesquisa das crenças sobre aprendizagem de línguas: estado da arte. Rev. Bras. Linguist. Apl., Belo Horizonte, 2001 [capturado 25 out. 2020]; 1(1):71-92. Disponível em:

http://www.scielo.br/scielo.php?script=sci arttext\&pid=S198463982001000100005\&lng=en\&nrm=iso DOI: https://doi.org/10.1590/S1984-63982001000100005.

Bock A, Furtado O, Teixeira M. Psicologias. 14르 ed. São Paulo: Saraiva; 2008.

Cabecinhas R. Representações sociais, relações intergrupais e cognição social. Paidéia (Ribeirão Preto), Ribeirão Preto, 2004 [capturado 27 out. 2020]. Aug;14,(28):125-137. Disponível em: http://www.scielo.br/scielo.php?script=sci arttext\&pid=S0103-

863X2004000200003\&lng=en\&nrm=iso. DOi: https://doi.org/10.1590/S0103-863X2004000200003. Acesso em: 27 de out. 2020.

Cunha AG. Dicionário Etimológico Nova Fronteira da Língua Portuguesa. $2^{\underline{a}}$ ed. Rio de Janeiro: Nova Fronteira; 1986.

Diniz AM. Sobre essas coisas a que chamamos crenças: para uma propedêutica da psicologia da crença. Forte da Casa: Climepsi Editores, 2004. [capturado 24 out. 2020] Disponível em: https://www.researchgate.net/profile/Antonio Diniz/publication/308048922 Sobre essas coisas a q ue chamamos crencas para uma propedeutica da psicologia da crenca/links/57d81933308ae5f03 b4984882/Sobre-essas-coisas-a-que-chamamos-crencas-para-uma-propedeutica-da-psicologia-dacrenca.pdf.

Dorsch F, Häcker H, Stapf KH. (Editores). Dicionário de Psicologia Dorsch. 4ª ed. Petrópolis: Vozes; 2009.

Garrido MV, Azevedo C, Palma T. Cognição social: fundamentos, formulações actuais e perspectivas futuras. Psicologia, Lisboa, 2011 [capturado 27 out. 2020]. jun;25(1):113-157. Disponível em: http://www.scielo.mec.pt/scielo.php?script=sci arttext\&pid=S0874-

20492011000100006\&lng=pt\&nrm=iso.

Guirado M. Clínica e transferência na sombra do discurso: uma analítica da subjetividade. Psicol. USP, São Paulo, 2015 [capturado 7 nov. 2020]. abr;26(1):108-117. Disponível em: $\quad$ http://www.scielo.br/scielo.php?script=sci arttext\&pid=S010365642015000100108\&lng=en\&nrm=iso. DOI: https://doi.org/10.1590/0103-656420140022

Krüger H. (Org.). Cognição Social: teoria, pesquisa e aplicações. Curitiba: CRV; 2018.

Krüger H. (Org.). Fundamentos da Psicologia Social. [Doutorado em Psicologia] - Fundação Getúlio Vargas (Instituto Superior de Estudos e Pesquisas Psicossociais - Centro de Pós-graduação em Psicologia). Rio de Janeiro; 1984.

Lara MLG. Diferenças conceituais sobre termos e definições e implicações na organização da linguagem documentária. Ci. Inf., Brasília, 2004 [capturado 23 out. 2020]. ago;33(2):9196. ago. 2004. Disponível em: http://www.scielo.br/scielo.php?script=sci arttext\&pid=S010019652004000200009\&lng=pt\&nrm=iso. DOI: http://dx.doi.org/10.1590/S0100-19652004000200009. 


\section{RECIMA21 - REVISTA CIENTÍFICA MULTIDISCIPLINAR}

Matos LS. "Segurança" Dicionário de Filosofia Moral e Política. Lisboa: Instituto de Filosofia da Nova, 2012. [capturado 18 out. 2020]. Disponível em: http://www.dicionariofmp-ifilnova.pt/.

Rodrigues A, Assmar EML, Jablonski B. Psicologia Social. 32ª ed. Petrópolis: Vozes; 2015.

Rokeach M. Crenças, atitudes e valores. Rio de Janeiro: Editora Interciência; 1981.

Santos AM. Segurança e Globalização: A Perspectiva dos Estudos Críticos de Segurança. Proelium $X \quad 2016$ [capturado 19 out. 2020]. (10):107-114. Disponível em: https://academiamilitar.pt/images/site images/Revista Proelium/07 Alvaro Santos.pdf.

Vandenbos GR, (Org.). Dicionário de Psicologia APA. Porto Alegre: Artmed; 2010. 